\title{
General metabolism of Laribacter hongkongensis: a genome-wide analysis
}

Shirly O Curreem ${ }^{1}$, Jade L Teng ${ }^{1}$, Herman Tse ${ }^{1,2,3,4}$, Kwok-Yung Yuen ${ }^{1,2,3,4}$, Susanna K Lau $u^{1,2,3,4^{*}}$ and Patrick C Woo $1,2,3,4^{*}$

\begin{abstract}
Background: Laribacter hongkongensis is associated with community-acquired gastroenteritis and traveler's diarrhea. In this study, we performed an in-depth annotation of the genes and pathways of the general metabolism of $L$. hongkongensis and correlated them with its phenotypic characteristics.
\end{abstract}

Results: The L. hongkongensis genome possesses the pentose phosphate and gluconeogenesis pathways and tricarboxylic acid and glyoxylate cycles, but incomplete Embden-Meyerhof-Parnas and Entner-Doudoroff pathways, in agreement with its asaccharolytic phenotype. It contains enzymes for biosynthesis and $\beta$-oxidation of saturated fatty acids, biosynthesis of all 20 universal amino acids and selenocysteine, the latter not observed in Neisseria gonorrhoeae, Neisseria meningitidis and Chromobacterium violaceum. The genome contains a variety of dehydrogenases, enabling it to utilize different substrates as electron donors. It encodes three terminal cytochrome oxidases for respiration using oxygen as the electron acceptor under aerobic and microaerophilic conditions and four reductases for respiration with alternative electron acceptors under anaerobic conditions. The presence of complete tetrathionate reductase operon may confer survival advantage in mammalian host in association with diarrhea. The genome contains CDSs for incorporating sulfur and nitrogen by sulfate assimilation, ammonia assimilation and nitrate reduction. The existence of both glutamate dehydrogenase and glutamine synthetase/ glutamate synthase pathways suggests an importance of ammonia metabolism in the living environments that it may encounter.

Conclusions: The L. hongkongensis genome possesses a variety of genes and pathways for carbohydrate, amino acid and lipid metabolism, respiratory chain and sulfur and nitrogen metabolism. These allow the bacterium to utilize various substrates for energy production and survive in different environmental niches.

\section{Background}

In 2001, Laribacter hongkongensis, a novel genus and species that belongs to the Neisseriaceae family of $\beta$ subclass of the Proteobacteria, was discovered from the blood and empyema pus of a patient with underlying alcoholic cirrhosis [1]. Subsequently, it was observed that L. hongkongensis was associated with freshwater fish borne community-acquired gastroenteritis and traveler's diarrhea in human [2-6]. In addition to its capability of living under both aerobic and anaerobic conditions and in the intestines of human, a variety of freshwater fish and frogs, it can also survive and replicate as a free living bacterium in water obtained from drinking water

\footnotetext{
* Correspondence: skplau@hkucc.hku.hk; pcywoo@hkucc.hku.hk

'Department of Microbiology, The University of Hong Kong, Hong Kong Full list of author information is available at the end of the article
}

reservoirs [6-10]. Despite its capability of survival in diverse environmental conditions, it does not metabolize any sugar tested $[1,3,4,11]$.

In this article, we present an overview of the general metabolism of L. hongkongensis based on the information obtained from its genome analysis. The metabolic pathways of $L$. hongkongensis were also compared to those of Neisseria gonorrhoeae, Neisseria meningitidis, Chromobacterium violaceum, Escherichia coli and Campylobacter jejuni. N. gonorrhoeae, N. meningitidis and C. violaceum are the other three bacterial species in the Neisseriaceae family of $\beta$-Proteobacteria with complete genome sequences available [12-15]. $N$. gonorrhoeae and $N$. meningitidis are strict aerobes that have stringent growth requirements and humans are their only known reservoir and host [16]. Conversely, C. violaceum is
C Biomed Central

() 2011 Curreem et al; licensee BioMed Central Ltd. This is an Open Access article distributed under the terms of the Creative Commons Attribution License (http://creativecommons.org/licenses/by/2.0), which permits unrestricted use, distribution, and reproduction in any medium, provided the original work is properly cited. 
facultative anaerobic, highly versatile in its metabolism, and can be found abundantly in multiple ecosystems, including water and soil; and in tropical and subtropical regions [17]. E. coli is the prototype Gram-negative bacterium with its metabolic pathways dissected in the greatest detail. C. jejuni is another Gram-negative, Sshaped, motile, asaccharolytic bacillus associated with gastroenteritis [18].

\section{Results and discussion}

The general metabolism discussed in this context mainly focuses on coding sequences (CDSs) that were classified into Cluster of Orthologous Groups (COG) functional categories of group $\mathrm{C}$ (energy production and conversion), G (carbohydrate transport and metabolism), E (amino acid transport and metabolism), I (lipid transport and metabolism) and $\mathrm{P}$ (inorganic ion transport and metabolism). Overall, the number of CDSs that were classified into these COGs was 191, 92, 253, 85 and 155 respectively in $L$. hongkongensis genome. These numbers are higher than those in $N$. gonorrhoeae and $N$. meningitidis genomes $(113,61,146,44$ and 96 CDSs respectively and 120, 67, 156, 52 and 96 CDSs respectively) but lower than those in C. violaceum genome (208, 203, 423, 139 and 226 CDSs respectively). This large number of genes in $C$. violaceum genome is in line with its ability to survive in a wide range of environments, whereas the relatively smaller number of genes in the genomes of $N$. gonorrhoeae and $N$. meningitidis reflects their fastidious growth requirements and limited host ranges. Phylogenetic relationship of L. hongkongensis and other bacteria that are included for comparative analysis in this study based on $16 \mathrm{~S}$ rRNA gene shows that L. hongkongensis is most similar to C. violaceum within the Neisseriaceae family with complete genome sequences available (Figure 1). This taxonomic closeness is also reflected in its gene contents, in which $L$. hongkongensis shares the highest percentage of CDSs with
C. violaceum $(64.1 \%)$ compared with other bacteria (Table 1).

Figure 2 illustrates the deduced central metabolism of L. hongkongensis from the genomic data. The reconstructed metabolic pathways reconciled the results of previous physiological and biochemical studies in light of the metabolic capacity of this strain and showed remarkable ability to adapt to diverse environment. Comparison with other Neisseriaceae bacteria, prototype $E$. coli and C. jejuni brings to light the unique capabilities of L. hongkongensis. Utilization of compounds as carbon and energy sources was more restricted than in C. violaceum, but more extended than $N$. meningitidis and N. gonorrhoeae.

\section{Carbohydrate metabolism}

In most bacteria, glucose is metabolized through Embden-Meyerhof-Parnas (EMP) pathway, a pathway that is also highly conserved in eukaryotes and archaea. Apart from EMP pathway, some prokaryotes adopt EntnerDoudoroff (ED) pathway for sugar metabolism by priming of 6-carbon sugars and subsequent cleavage into two 3-carbon intermediates by aldolase enzymes [19]. While some bacteria, such as E. coli and Pseudomonas aeruginosa, have genes for both EMP and ED pathways, others contain only either one of them, or each pathway is dedicated for the metabolism of specific 6-carbon sugar [19]. In L. hongkongensis, both pathways were incomplete with regards to the predicted genes present in the genome (Figure 2). The absence of hexokinase, 6phosphofructokinase and pyruvate kinase, which are key enzymes of EMP pathway, suggested that the bacterium cannot catabolize glucose through EMP pathway, in agreement with its asaccharolytic phenotype. Similar observations are found in other asaccharolytic bacteria such as C. jejuni, Bordetella pertussis, Bordetella parapertussis and Bordetella bronchiseptica, in which the genes encoding glucokinase and 6-phosphofructokinase

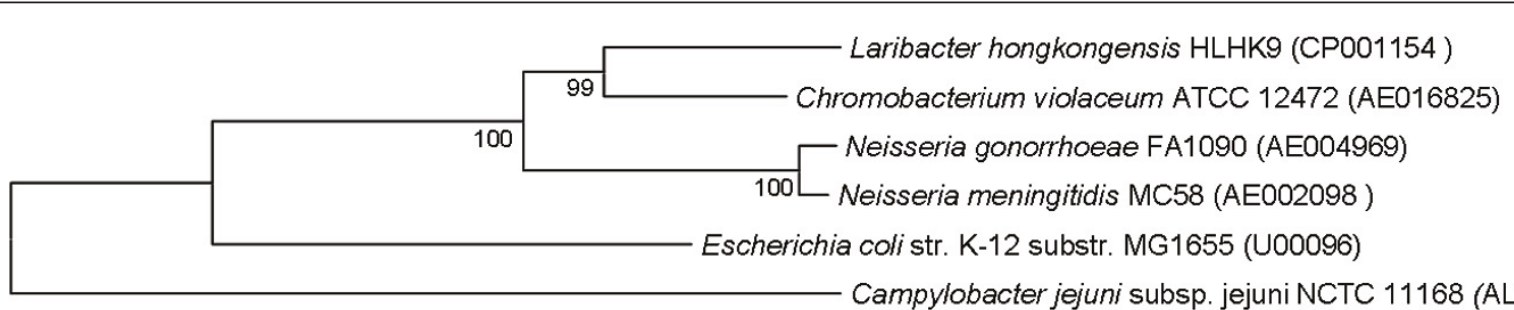

Campylobacter jejuni subsp. jejuni NCTC 11168 (AL111168)

\section{$\longmapsto .02$}

Figure 1 Phylogenetic relationship of 16S rRNA among L. hongkongensis HLHK9, N. meningitidis MC58, N. gonorrhoeae FA 1090, C. violaceum ATCC 12472, E. coli K12 MG1655 and C. jejuni NCTC 11168. The tree was inferred from 16S rRNA data by the neighbor-joining method. Bootstrap values were calculated from 1,000 trees. The scale bar indicates the estimated number of substitutions per 50 bases. Names and accession numbers are given as cited in the GenBank database. 
Table 1 Gene contents in L. hongkongensis, N. meningitidis, N. gonorrhoeae, C. violaceum, E. coli and C. jejuni

\begin{tabular}{|c|c|c|c|c|c|c|}
\hline & $\begin{array}{l}\text { L. hongkongensis } \\
\text { HLHK9 }\end{array}$ & $\begin{array}{l}\text { C. violaceum ATCC } \\
12472\end{array}$ & $\begin{array}{l}\text { N. gonorrhoeae } \\
\text { FA } 1090\end{array}$ & $\begin{array}{l}\text { N. meningitidis } \\
\text { MC58 }\end{array}$ & $\begin{array}{l}\text { E. coli K12 } \\
\text { MG1655 }\end{array}$ & $\begin{array}{l}\text { C. jejuni } \\
\text { NCTC } 11168\end{array}$ \\
\hline Total number of CDSs & 3235 & 4407 & 2002 & 2143 & 4321 & 1647 \\
\hline $\begin{array}{l}\text { With homologues in L. } \\
\text { hongkongensis }\end{array}$ & - & $\begin{array}{l}64.1 \% \\
(2075 / 3235)\end{array}$ & $\begin{array}{l}39.6 \% \\
(1282 / 3235)\end{array}$ & $\begin{array}{l}40.0 \% \\
(1295 / 3235)\end{array}$ & $\begin{array}{l}50.4 \% \\
(1629 / 3235)\end{array}$ & $\begin{array}{l}24.6 \% \\
(795 / 3235)\end{array}$ \\
\hline \multicolumn{7}{|l|}{ RNA gene } \\
\hline \multicolumn{7}{|l|}{ rRNA genes } \\
\hline $5 S$ rRNA & 7 & 9 & 4 & 4 & 8 & 3 \\
\hline $16 \mathrm{~S}$ rRNA & 7 & 8 & 4 & 4 & 7 & 3 \\
\hline $23 \mathrm{~S}$ rRNA & 7 & 8 & 4 & 4 & 7 & 3 \\
\hline tRNA genes & 78 & 98 & 55 & 59 & 89 & 44 \\
\hline
\end{tabular}

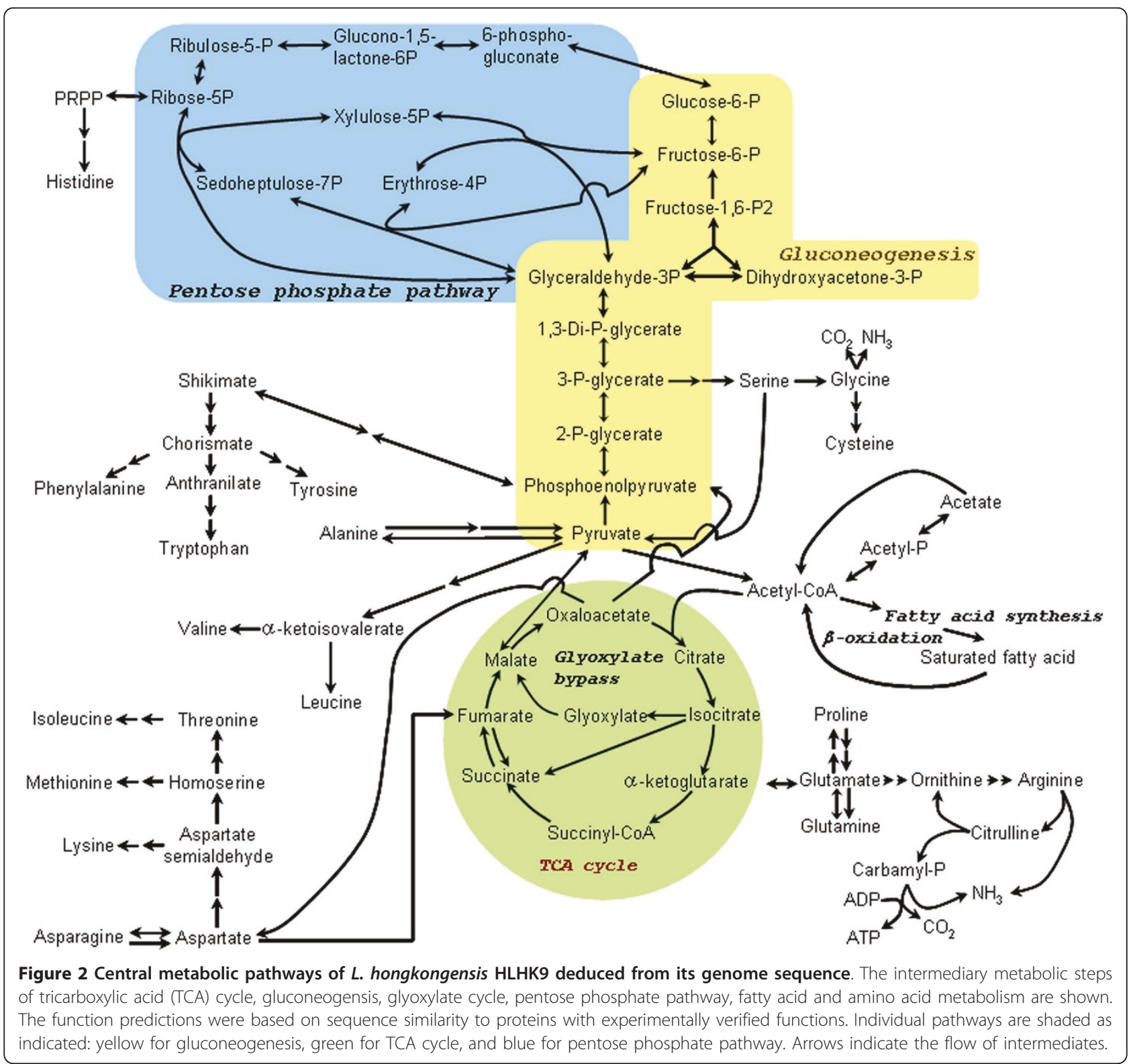


are also absent from their genomes [15,20]. For $N$. gonorrhoeae and N. meningitidis, although they both metabolize a variety of sugars, their genomes do not contain 6-phosphofructokinase gene. Instead, they use ED pathway for metabolizing the 6-carbon sugars $[12,21]$. In the genome of L. hongkongensis, the gene that encodes one (2-keto-3-deoxy-6-phosphogluconate aldolase), but not the other (6-phosphogluconate dehydratase), of the two key enzymes of ED pathway is present, suggesting an incomplete pathway exists for metabolizing 6-carbon sugars through this pathway. With the inability to utilize exogenous carbohydrates, it is thus expected that gluconeogenesis would be essential to generate 6-carbon intermediates required for other biosynthetic pathways in $L$. hongkongensis, and the presence of complete gluconeogenic genes is coherent with this prediction (Figure 2).

In line with the asaccharolytic nature of L. hongkongensis and $C$. jejuni, both genomes do not contain genes that encode a complete phosphoenolpyruvate-dependent, sugar transporting phosphotransferase system (PTS), one of the major carbohydrate transport systems in bacteria. The genome of L. hongkongensis contains genes that encode enzyme I, phosphocarrier protein HPr, HPr kinase/phosphorylase HPrK, enzyme IIA ${ }^{\text {Ntr }}$ and enzyme IIA ${ }^{\text {fru }}$, whereas none of the genes that encode any of the components of PTS is present in the genome of $C$. jejuni [15]. Similar to L. hongkongensis, $N$. meningitidis and $N$. gonorrhoeae also contain cytoplasmic PTS protein homologues including EI, NPr (a variant of HPr) and HPrK together with incomplete enzyme II homologues although they were both saccharolytic. The presence of other sugar permeases in their genome suggests that sugars are probably transported through other pathways. In the genomes of $C$. violaceum and E. coli, genes encoding complete PTS protein homologues (enzyme I and HPr) and multiple types of enzyme II permeases are present, compatible with their ability to use a large number of sugars [13,14]. In general, enzyme I and HPr are energy coupling proteins of the system while complete enzyme II complexes, PTS permeases, consist of IIA, IIB and IIC domains (as well as IID domain in the family of mannose). Instead of carbohydrate transport, some enzymes may be involved in regulation [22]. The presence of enzyme IIA $^{\mathrm{Ntr}}$ and enzyme IIA ${ }^{\text {fru }}$ in L. hongkongensis suggested that they are probably needed for the regulation of other biochemical pathways rather than sugar transport.

Genes encoding enzymes of both non-oxidative and oxidative branches of pentose phosphate pathway (PPP) and TCA cycle can be found in the genome of L. hongkongensis, C. violaceum and E. coli, whereas $C$. jejuni lacks the oxidative branch of PPP [11-15]. Although genes that encode enzymes for PPP and most of TCA cycle are present in the genomes of $N$. meningitidis and $N$. gonorrhoeae, the gene for malate dehydrogenase is absent from both genomes. The presence of flavin adenine dinucleotide (FAD)-dependent malate:quinine oxidoreductase may substitute for the reaction catalyzed by malate dehydrogenase by oxidizing malate to oxaloacetate, yet experimental analysis awaits to confirm such prediction [21]. When carbon sources are metabolized to acetyl-coenzyme A (acetylCoA) instead of pyruvate or phosphoenolpyruvate, TCA cycle intermediates cannot be replenished through anaplerotic reactions. A complete pathway for glyoxylate cycle found in L. hongkongensis provides a simple and efficient strategy for it to convert acetyl$\mathrm{CoA}$ into anaplerotic and gluconeogenic compounds and enables it to grow with C-2 compounds as the sole carbon source. With glyoxylate pathway, gluconeogenesis, non-oxidative PPP and anaplerotic reactions, L. hongkongensis will therefore be able to generate different intermediates required for biosynthetic metabolism. The presence of critical anaplerotic enzymes, including phosphoenolpyruvate synthase and phosphoenolpyruvate carboxylase, which convert pyruvate and oxaloacetate respectively to phosphoenolpyruvate, together with malate oxidoreductase in $L$. hongkongensis reflects its potential to grow on carbon sources such as malate (Table 2). Malate, together with succinate and fumarate, are $\mathrm{C}_{4}$-dicarboxylates. They are intermediates in TCA cycle that can be utilized by bacteria such as E. coli, B. subtilus and many Rhizobium spp. as nonfermentable carbon and/or energy sources under aerobic or anaerobic conditions [23]. A number of $\mathrm{C}_{4}$-dicarboxylates can be found in nature such as fermentation products (e.g. succinate) and complexing agents (e.g. oxalate and malate) [24]. The presence of several $\mathrm{C}_{4}$-dicarboxylates transporters reinforces the prediction of using $\mathrm{C}_{4}$-dicarboxylates as carbon sources in L. hongkongensis. This is in line with our experiments on minimal medium for L. hongkongensis which showed that L-malate can be used as sole carbon source [11].

\section{Amino acid metabolism}

Similar to E. coli and C. jejuni, but not N. gonorrhoeae, $N$. meningitidis and C. violaceum, the genome of L. hongkongensis contains enzymes for biosynthesis of all 20 universally found amino acids and also selenocysteine. Selenocysteine $(\mathrm{Sec})$ is an amino acid present in many species in three domains of life $[25,26]$. It is encoded by opal codon (UGA), of which selenoprotein mRNA carries a selenocysteine insertion sequence element immediately downstream to the selenocysteine-encoding UGA codon [27]. Biosynthesis and incorporation of selenocysteine requires four genes, including selA (encoding Sec 
Table 2 CDSs related to anaplerotic reactions in L. hongkongensis, N. meningitidis, N. gonorrhoeae, C. violaceum, E. coli and C. jejuni

\begin{tabular}{|c|c|c|c|c|c|c|c|}
\hline Enzyme & Gene & $\begin{array}{l}\text { L. hongkongensis } \\
\text { HLHK9 }\end{array}$ & $\begin{array}{l}\text { C. violaceum } \\
\text { ATCC } 12472\end{array}$ & $\begin{array}{l}\text { N. gonorrhoeae } \\
\text { FA } 1090\end{array}$ & $\begin{array}{l}\text { N. meningitidis } \\
\text { MC58 }\end{array}$ & $\begin{array}{l}\text { E. coli K12 } \\
\text { MG1655 }\end{array}$ & $\begin{array}{l}\text { C. jejuni } \\
\text { NCTC } 11168\end{array}$ \\
\hline $\begin{array}{l}\text { Phosphoenolpyruvate } \\
\text { carboxylase }\end{array}$ & $p p c$ & + & + & + & + & + & - \\
\hline $\begin{array}{l}\text { Phosphoenolpyruvate } \\
\text { synthase }\end{array}$ & pps & + & + & + & + & + & - \\
\hline $\begin{array}{l}\text { Phosphoenolpyruvate } \\
\text { carboxykinase }\end{array}$ & $p c k$ & - & - & - & - & + & + \\
\hline $\begin{array}{l}\text { Malate oxidoreductase } \\
\text { (EC 1.1.1.38) }\end{array}$ & maeA & - & - & + & + & + & + \\
\hline $\begin{array}{l}\text { Malate oxidoreductase } \\
\text { (EC 1.1.1.40) }\end{array}$ & maeB & + & + & - & - & + & - \\
\hline
\end{tabular}

synthase), selB (encoding Sec-specific elongation factor), selC (encoding tRNA ${ }^{\mathrm{Sec}}$ ) and selD (encoding selenophosphate synthetase), whereas $y b b B$ (encoding tRNA 2selenouridine synthase) is needed for utilization. All the genes required for biosynthesis and incorporation of selenocysteine are present in the genomes of about $20 \%$ of bacteria with complete genome sequence available, with a majority in Proteobacteria and Firmicutes [28]. While L. hongkongensis is predicted to synthesize selenocysteine, such ability is not found in C. violaceum, $N$. gonorrhoeae and $N$. meningitidis which also belong to $\beta$ Proteobacteria. Although the reason for the selective presence of selenocysteine in some organisms remains unknown, it is usually present in the active sites of proteins with redox functions [27]. From the genomic data, it is predicted that only the most commonly found selenoprotein, alpha subunit of formate dehydrogenase encoded by fdoG, is present in L. hongkongensis using a selenoprotein prediction software bSECISearch $[28,29]$.

Similar to C. jejuni, the genome of L. hongkongensis contains a number of proteases, peptidases and transporters for degradation and transport of proteins or peptides into oligopeptides or amino acids. The amino acids can then be degraded intracellularly by various enzymes (Table 3). These amino acids can be used as carbon and nitrogen source for the bacterium. The products of the reactions can enter central metabolic pathways including TCA cycle and gluconeogenesis pathway, and can be used for anabolic and catabolic purposes (Figure 2 and Table 3).

As predicted from the genomic sequence, several genes involved in the biosynthesis (amino-acid acetyltransferase gene $\operatorname{argA}$ : LHK_02338, LHK_02366; acetylglutamate kinase gene argB: LHK_02337, LHK_02829) and catabolism (whole operon of arginine deiminase

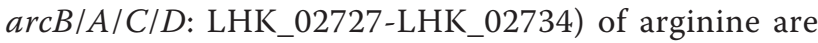
duplicated in L. hongkongensis, suggesting the importance of arginine metabolism in the bacterium. Previously, we have shown that the two isoenzymes of
$N$-acetyl-L-glutamate kinase (NAGK) encoded by duplicated copies of argB, NAGK-20 and NAGK-37, which catalyze the key reaction in the 8-step arginine biosynthesis, gave differential expression pattern in a comparative proteomic study of L. hongkongensis growing at $37^{\circ}$ $\mathrm{C}$ (human body temperature) and $20^{\circ} \mathrm{C}$ (freshwater habitat temperature) [11]. With NAGK-20 showing a higher expression at $20^{\circ} \mathrm{C}$ and NAKG-37 showing a higher expression at $37^{\circ} \mathrm{C}$, kinetic analysis revealed that NAGK20 also had a lower optimal temperature for enzymatic activities and was inhibited by arginine whereas NAGK37 had a higher enzymatic activity with a higher optimal temperature and was insensitive to arginine inhibition [11]. These observations suggest the two isoenzymes are involved in temperature adaptation. Further investigation into the functions of duplicated genes in the metabolic pathway of arginine should yield fruitful insights into the lifestyle of $L$. hongkongensis.

\section{Lipid metabolism}

Fatty acids are synthesized via repeated cycles of condensation, dehydration and reduction of carbon-carbon bonds. While the majority of bacterial membranes are composed of saturated fatty acids, presence of unsaturated fatty acids (UFAs) can increase the fluidity of the membrane [30,31]. Similar to the genomes of the other five bacteria, the genome of $L$. hongkongensis contains all the enzymes for biosynthesis of saturated fatty acids (Table 4). As for UFA biosynthesis, there are two known sets of enzymes that operate by different mechanisms: aerobic route and anaerobic route [32]. In the aerobic route, UFAs are formed by the oxidation of saturated fatty acids catalyzed by acyl-ACP oxidase (fatty acid desaturase). In the anaerobic route, trans double bond is introduced to the acyl chain of ß-hydroxy-decanoyl-ACP and isomerized to cis-3-decenoyl-ACP by bifunctional 3-hydroxydecanoyl-ACP dehydratase/isomerase (FabA) (encoded by $f a b A$ ), followed by 3-ketoacyl-ACP synthase I (FabB) (encoded by fabB) 
Table 3 Amino acid catabolism of $L$. hongkongensis HLHK9 deduced from its genome sequence

\begin{tabular}{|c|c|c|c|c|}
\hline $\begin{array}{l}\text { Amino } \\
\text { acid }\end{array}$ & Pathway/enzyme(s) involved & Gene number & Intermediates/products formed & $\begin{array}{l}\text { Pathways that intermediates } \\
\text { enter }\end{array}$ \\
\hline Serine & L-serine dehydratase & LHK_02265 & Pyruvate, ammonia & TCA cycle or gluconeogenesis \\
\hline \multirow[t]{4}{*}{ Aspartate } & Argininosuccinate synthase & LHK_02172 & $\begin{array}{l}\text { Fumarate, oxaloacetate, ammonia, } \\
\text { ATP }\end{array}$ & TCA cycle \\
\hline & Argininosuccinate lyase & LHK_03122 & & \\
\hline & L-aspartate oxidase & LHK_00001 & & \\
\hline & Aspartate aminotransferase & LHK_01340 & & \\
\hline \multirow[t]{2}{*}{ Glutamine } & Glutamine synthetase & LHK_01876 & $\alpha$-ketoglutarate, ammonia & TCA cycle \\
\hline & Glutamate dehydrogenase & LHK_01886 & & \\
\hline \multirow[t]{3}{*}{ Glycine } & Glycine cleavage system P-protein & LHK_02722 & Ammonia, $\mathrm{CO}_{2}, \mathrm{NADH}$ & Ammonia assimilation \\
\hline & Glycine cleavage system $\mathrm{H}$ protein & LHK_02723 & & \\
\hline & Glycine cleavage system T protein & LHK_02724 & & \\
\hline \multirow[t]{3}{*}{ Alanine } & Alanine dehydrogenase & LHK_02210 & Pyruvate & TCA cycle or gluconeogenesis \\
\hline & Alanine racemase & LHK_00350 & & \\
\hline & D-amino acid dehydrogenase & LHK_00934 & & \\
\hline Glutamate & Glutamate dehydrogenase & LHK_01886 & $\alpha$-ketoglutarate, ammonia & TCA cycle \\
\hline \multirow[t]{7}{*}{ Arginine } & Arginine deiminase pathway & & Ammonia, ATP & Ammonia assimilation \\
\hline & Arginine deiminase & $\begin{array}{l}\text { LHK_02729, } \\
\text { LHK_02734 }\end{array}$ & & \\
\hline & Ornithine carbamoyltransferase & $\begin{array}{l}\text { LHK_02728, } \\
\text { LHK_02733 }\end{array}$ & & \\
\hline & Carbamate kinase & $\begin{array}{l}\text { LHK_02727, } \\
\text { LHK_02732 }\end{array}$ & & \\
\hline & Arginine decarboxylase pathway & & Putrescine & TCA cycle \\
\hline & Arginine decarboxylase & LHK_01034 & & \\
\hline & Agmatinase & LHK_01140 & & \\
\hline \multirow[t]{2}{*}{ Proline } & Proline dehydrogenase & LHK_01861 & $\alpha$-ketoglutarate, ammonia & TCA cycle \\
\hline & $\begin{array}{l}\text { 1-pyrroline carboxylate } \\
\text { dehydrogenase }\end{array}$ & LHK_01861 & & \\
\hline
\end{tabular}

which catalyzes the elongation of cis-3-decenoyl-ACP to form UFAs. This pathway is well-studied in E. coli $[32,33]$. The presence of either mechanism is sufficient for the biosynthesis of UFA. Unlike C. violaceum, which has the genes for the aerobic UFA biosynthetic pathway, the genome of L. hongkongensis does not contain the gene that encodes desaturase. As for the anaerobic route, $f a b A-f a b B$ is generally restricted to genomes of $\alpha$ and $\gamma$-Proteobacteria. Therefore, it is not surprising that the genomes of $L$. hongkongensis, $N$. gonorrhoeae, $N$. meningitidis and $C$. violaceum and that of $C$. jejuni ( $\varepsilon-$ Proteobacteria) do not contain $f a b A-f a b B$. Alternative pathways for anaerobic UFA biosynthesis in the absence of $f a d A$ and $f a d B$ have been reported in other bacteria

Table 4 Comparison of metabolic pathways for fatty acid metabolism deduced from the genomes of $L$. hongkongensis, N. meningitidis, N. gonorrhoeae, C. violaceum, E. coli and C. jejuni

\begin{tabular}{|c|c|c|c|c|c|c|}
\hline Pathway & $\begin{array}{l}\text { L. hongkongensis } \\
\text { HLHK9 }\end{array}$ & $\begin{array}{l}\text { C. violaceum ATCC } \\
12472\end{array}$ & $\begin{array}{l}\text { N. gonorrhoeae } \\
\text { FA } 1090\end{array}$ & $\begin{array}{l}\text { N. meningitidis } \\
\text { MC58 }\end{array}$ & $\begin{array}{l}\text { E. coli K12 } \\
\text { MG1655 }\end{array}$ & $\begin{array}{l}\text { C. jejuni NCTC } \\
11168\end{array}$ \\
\hline \multicolumn{7}{|l|}{ Fatty acid biosynthesis } \\
\hline Saturated fatty acid & + & + & + & + & + & + \\
\hline $\begin{array}{l}\text { Unsaturated fatty } \\
\text { acid }\end{array}$ & - & + & - & - & + & - \\
\hline $\begin{array}{l}\text { Cyclopropane fatty } \\
\text { acid }\end{array}$ & + & + & - & - & + & + \\
\hline \multicolumn{7}{|l|}{ Fatty acid catabolism } \\
\hline Saturated fatty acid & + & + & - & - & + & - \\
\hline $\begin{array}{l}\text { Unsaturated fatty } \\
\text { acid }\end{array}$ & - & + & - & - & + & - \\
\hline
\end{tabular}


such as Streptococcus pneumoniae and Enterococcus faecalis, in which a trans-2 to cis-3-decenoyl-ACP isomerase (FabM) can introduce a cis double bond into the growing acyl chain in the former and the presence of homologues of FabZ and FabF that can function as FabA and FabB in the latter $[34,35]$. Other options such as dual functions of FabF involved in saturated fatty acid biosynthesis as FabF and UFA biosynthesis as FabB has also been reported in Clostridium acetobutylicium and Lactococcus lactis [36,37]. While L. hongkongensis contains neither of the alternative $f a b A, f a b B$ and $f a b M$ genes in its genome, whether its FabF has dual function is yet to be determined. This phenomenon has also been observed in the genomes of $N$. gonorrhoeae and $N$. meningitidis. It has been suggested that there may be uncharacterized enzymes and pathways for unsaturated fatty acid biosynthesis in these bacteria [38]. Analysis of membrane phospholipids in L. hongkongensis will reveal the types of unsaturated fatty acids that it possesses and help to delineate the possible biosynthetic pathway.

In addition, the presence of two homologues of cyclopropane fatty-acyl-phospholipid synthases (LHK_01324 and LHK_03103) (CFA synthase) suggested the possibility for L. hongkongensis to synthesize cyclopropane fatty acid. Cyclopropane fatty acids are found in the bacterial membrane and are believed to be involved in acid resistance in E. coli and in association with virulence and persistence of Mycobacterium tuberculosis in host $[39,40]$.

For the catabolism of fatty acids, genes that encode complete set of enzymes for $\beta$-oxidation pathway of saturated fatty acids are present in the genome of $L$. hongkongensis (Table 4). This suggests that L. hongkongensis may utilize these fatty acids as an energy source. The product of $\beta$-oxidation of saturated fatty acids, acetyl-CoA, will enter TCA cycle. On the other hand, similar to N. gonorrhoeae, N. meningitidis and C. jejuni, the genome of $L$. hongkongensis does not contain any of the two genes that encode enzymes for catabolism of unsaturated fatty acids (Table 4).

\section{Respiratory chain}

The constituents of the respiratory chain of L. hongkongensis dissected under aerobic and anaerobic growth conditions revealed the metabolic potential to obtain energy from various sources. The primary function of respiratory chain of bacteria is to produce ATP through the transport of electrons from various electron donors, usually intermediates of metabolic pathways linked by quinones or ubiquinones, to various electron acceptors. The proton gradient generated between the cytoplasm and periplasm is then dissipated for ATP synthesis by $\mathrm{F}_{1} \mathrm{~F}_{0}$ ATP synthase, which is predicted to be present in the genomes of $L$. hongkongensis and the other 5 species compared in this context [32]. The genome of L. hongkongensis contains a plethora of dehydrogenases, including NADH dehydrogenase I, Rnf type electron transport complex, succinate dehydrogenase, formate dehydrogenase, proline dehydrogenase, electron-transferring flavoprotein dehydrogenase, and D-amino acid dehydrogenase (Table 5). A variety of substrates as electron donors, such as NADH, succinate, formate, proline, acyl-CoA and D-amino acids appears to be utilized. The Rnf type electron transport complex was found in the genomes of L. hongkongensis and E. coli, but not those of $N$. gonorrhoeae, $N$. meningitidis, C. violaceum and $C$. jejuni. The complex was first discovered in Rhodobacter capsulatus in 1993 [41]. Although its role is not fully established, it was proposed to be an alternative enzyme to NADH dehydrogenase for utilizing NADH as the electron donor and had been found in many bacteria [42-44].

As for the final step of the respiratory chain, L. hongkongensis genome encodes three terminal cytochrome oxidases, namely type $a a_{3}$ oxidase (a haem-copper oxidase), type $c b b_{3}$ oxidase (another haem-copper oxidase) and type $b d$ oxidase (a quinol oxidase). These three cytochrome oxidases are responsible for carrying out respiration using oxygen as the electron acceptor under aerobic conditions (type $a a_{3}$ oxidase) and conditions with reduced oxygen tension (type $c b b_{3}$ and type $b d$ oxidases) (Table 5). Among the three cytochrome oxidases, type $c b b_{3}$ oxidase is the most ancient one and is present in almost all Proteobacteria except anaerobic $\delta$-Proteobacteria [45]. It is characterized by the high affinity for oxygen which is needed in microaerobic environment. In addition to cytochrome oxidases, L. hongkongensis genome also encodes a number of reductases [fumarate reductase, nitrate reductase, dimethylsulfoxide (DMSO) reductase and tetrathionate reductase], which allow the bacterium to carry out respiration with several alternative electron acceptors to oxygen (fumarate, nitrate, DMSO and tetrathionate) under anaerobic conditions (Table 5). The presence of versatile reductases may give clues to the living habitats of the bacterium where alternative electron acceptors can be found in that environment. The presence of DMSO reductase and tetrathionate reductase is of particular interest. DMSO is abundant in aquatic environments which can be produced from the photochemical oxidation of dimethyl sulfide (DMS) and also from eukaryotic microplankton $[46,47]$. It may reflect the environment where $L$. hongkongensis is found. As for tetrathionate reductase, the presence of a complete $t$ tr gene cluster suggested that tetrathionate can be used as an electron acceptor during anaerobic reduction of tetrathionate to thiosulfate. Notably, L. hongkongensis is the only bacterium that contains the ttr operon among the family Neisseriaceae members 
Table 5 Comparison of components of the respiratory chains deduced from the genomes of $L$. hongkongensis, $N$. meningitidis, N. gonorrhoeae, C. violaceum, E. coli and C. jejuni

\begin{tabular}{|c|c|c|c|c|c|c|}
\hline Pathway/enzymes & $\begin{array}{l}\text { L. hongkongensis } \\
\text { HLHK9 }\end{array}$ & $\begin{array}{l}\text { C. violaceum } \\
\text { ATCC } 12472\end{array}$ & $\begin{array}{l}\text { N. gonorrhoeae } \\
\text { FA } 1090\end{array}$ & $\begin{array}{l}\text { N. meningitidis } \\
\text { MC58 }\end{array}$ & $\begin{array}{l}\text { E. coli K12 } \\
\text { MG1655 }\end{array}$ & $\begin{array}{l}\text { C. jejuni NCTC } \\
11168\end{array}$ \\
\hline \multicolumn{7}{|l|}{ Electron donors } \\
\hline NADH dehydrogenase $e^{a}$ & I & I and || & I and || & | and || & I and || & $1^{b}$ \\
\hline Succinate dehydrogenase & + & + & + & + & + & + \\
\hline $\begin{array}{l}\text { Rnf-type electron transport } \\
\text { complex }\end{array}$ & + & - & - & - & + & - \\
\hline Formate dehydrogenase & + & + & - & - & + & + \\
\hline Proline dehydrogenase & + & + & + & + & + & + \\
\hline $\begin{array}{l}\text { Electron-transferring flavoprotein } \\
\text { dehydrogenase }\end{array}$ & + & + & + & + & + & - \\
\hline D-amino acid dehydrogenase & + & + & + & + & + & - \\
\hline \multicolumn{7}{|l|}{$\begin{array}{l}\text { Electron acceptors for aerobic } \\
\text { respiration }\end{array}$} \\
\hline Cytochrome oxidase (aa 3 type) & + & + & - & - & + & - \\
\hline Cytochrome oxidase ( $\mathrm{Cb}_{3}$ type) & + & + & + & + & - & + \\
\hline Cytochrome oxidase (bd type) & + & + & - & - & + & + \\
\hline \multicolumn{7}{|l|}{$\begin{array}{l}\text { Electron acceptors for anaerobic } \\
\text { respiration }\end{array}$} \\
\hline $\begin{array}{l}\text { Periplasmic nitrate reductase } \\
\text { Nap type }\end{array}$ & + & napA only ${ }^{c}$ & - & - & + & + \\
\hline Nitrate reductase Nar type & - & + & - & - & + & - \\
\hline Fumarate reductase & + & + & + & + & + & + \\
\hline DMSO reductase & + & - & - & - & + & - \\
\hline Tetrathionate reductase & + & - & - & - & - & - \\
\hline $\mathrm{F}_{1} \mathrm{~F}_{0} \mathrm{ATP}$ synthase & + & + & + & + & + & + \\
\hline
\end{tabular}

${ }^{a}$ Two types of $\mathrm{NADH}$ dehydrogenases (NDH) can function in the respiratory complex I in bacteria. Type I NDH is a proton pumping NADH:ubiquinone oxidoreductase that transfer electron from NADH to ubiquinone for generation of electrochemical proton gradient [75]. Type II NDH is a monomeric enzyme in which NADH oxidation is not coupled to proton pumping [76].

${ }^{\mathrm{b}}$ The gene cluster that encodes NADH dehydrogenase I in most bacteria are consisted of 14 different genes. C. jejuni contains 12 of the 14 genes in which nuoE and nuoF are absent [15].

${ }^{\mathrm{C}}$ The basic gene components for periplasmic Nap type nitrate reductase to be regarded as functional are napABCD [68]. $C$. violaceum contains only napA.

with complete genome sequences available (LHK_01476LHK_01478). Unlike the genes for carbohydrate, lipid and amino acid metabolism and those of the respiratory chain which are phylogenetically most related to other members of the Neisseriaceae, these three genes are most similar to their homologues in Thiobacillus denitrificans ATCC 25259 and Aromatoleum aromaticum EbN1 which were both $\beta$-Proteobacteria (Figure 3, 4 and 5) $[48,49]$. The ability to respire tetrathionate is the characteristics of certain genera of Enterobacteriaceae including Salmonella, Citrobacter, Yersinia and Proteus [50]. It was recently reported that tetrathionate respiration provided growth benefit to $S$. Typhimurium in the lumen of inflamed intestine over other commensals/ microbiota inhabited in the gut [51]. Previously, only the source of thiosulfate, but not tetrathionate, was known in mammalian hosts. Toxic hydrogen sulphide gas produced by colonic bacteria in the intestine is detoxified by colonic muscosa into thiosulfates, thus a large quantity is present in the intestinal lumen $[52,53]$.
It is now established that thiosulfate can be converted to tetrathionate upon reaction with reactive oxygen species that are generated during inflammation [51]. The presence of complete $t$ tr gene cluster in L. hongkongensis genome suggests that it may confer survival advantage in mammalian host in association with diarrhea. On the other hand, the source of tetrathionate in nature is not clear, but it seems likely to occur in bacterial communities that include sulfate-reducing bacteria as it has been detected in humid soils that support growth of such bacteria [50].

\section{Sulfur metabolism}

Sulfur is a constituent of amino acids cysteine and methionine, and also found in various coenzymes and other metabolites. The major form of inorganic sulfur in nature, sulfate, is usually incorporated into bacteria as organic compound through the pathway of sulfate assimilation. With the ability to synthesize L-cysteine and L-methionine, L. hongkongensis is expected to 


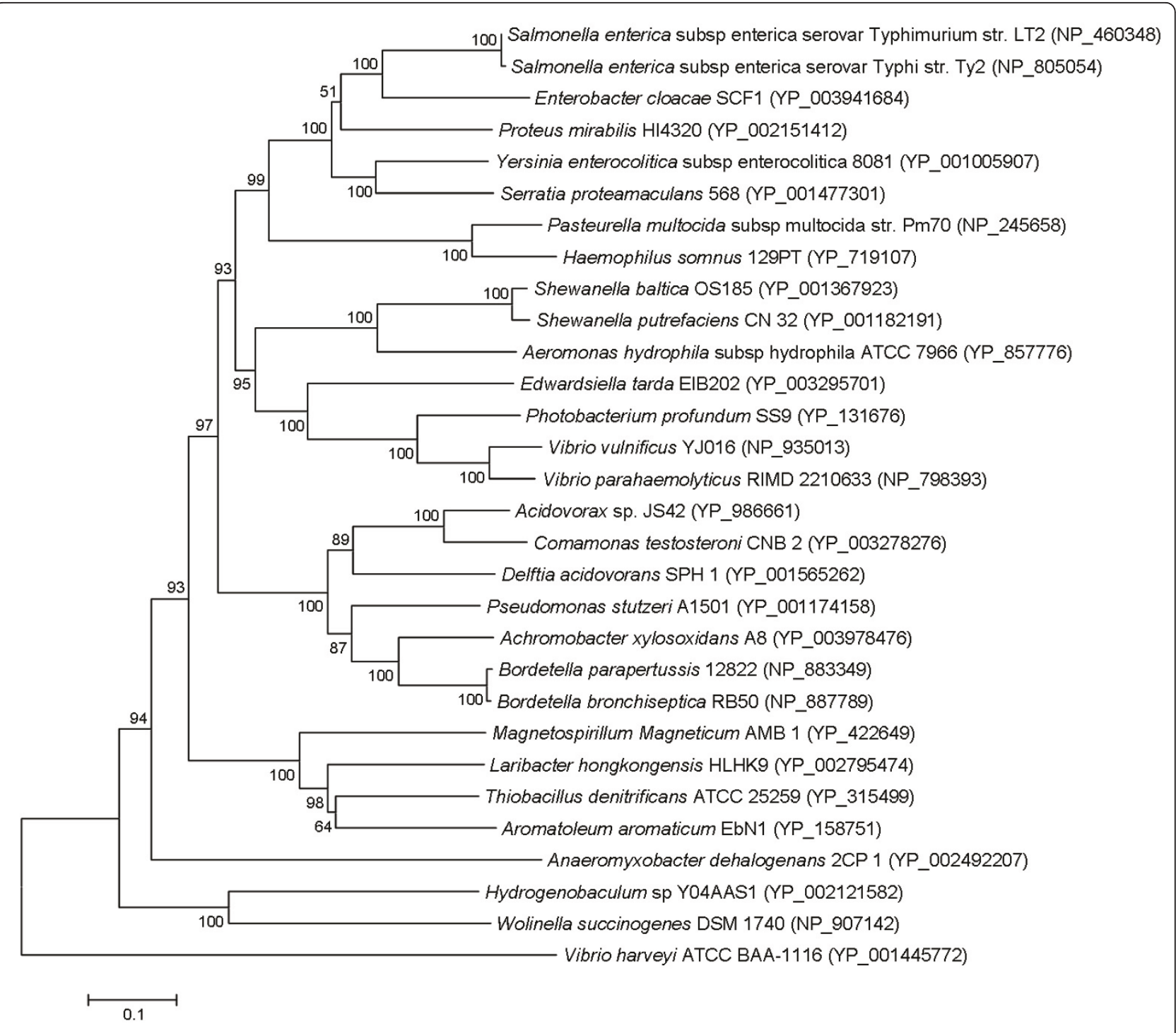

Figure 3 Phylogenetic analysis of ttrA encoded protein in tetrathionate reductase gene cluster in L. hongkongensis HLHK9. Phylogenetic tree showing the relationship of ttrA encoded proteins of L. hongkongensis HLHK9 to other species with complete ttr gene cluster constructed by neighbor-joining method. Bootstrap values were calculated from 1000 trees. The scale bar indicates the estimated number of substitutions per 10 amino acids. All names and accession numbers are given as cited in the GenBank database.

undergo sulfate assimilation with reduction of inorganic sulfate to sulfide and enter L-cysteine and L-methionine biosynthetic pathways. There are two pathways for intracellular sulfate to be reduced to sulfite and further to sulfide in bacteria, which differ in the form of activated sulfate as input (Figure 6A). The first pathway, commonly but not exclusively found in enteric bacteria such as E. coli and traditionally assumed to be used by the majority of bacteria, converts adenosine 5'-adenylylsulfate (APS) to 3'-phosphoadenylylsulfate (PAPS) via adenylylsulfate kinase CysC, where PAPS is eventually reduced to sulfite by PAPS reductase [54]. On the other hand, the second pathway which was originally identified in plants and subsequently found in other bacterial taxa including $P$. aeruginosa, other members of $\alpha$-, $\beta$ - and $\gamma$-Proteobacteria and $M$. tuberculosis, reduces APS to sulfite directly by APS reductase [55,56]. Bacterial PAPS reductase and APS reductase are highly homologous and the major difference is the presence of conserved two-cysteine motifs in APS reductase [55-57]. Phylogenetic analysis showed that APS reductase from plant and many bacteria such as Pseudomonas, Rhizobium (Sinorhizobium) and M. tuberculosis clustered together [55]. The enzyme is also assumed to be typical in $\beta$-Proteobacteria as phylogenetic analysis of the gene components suggests that homologues of APS reductase 


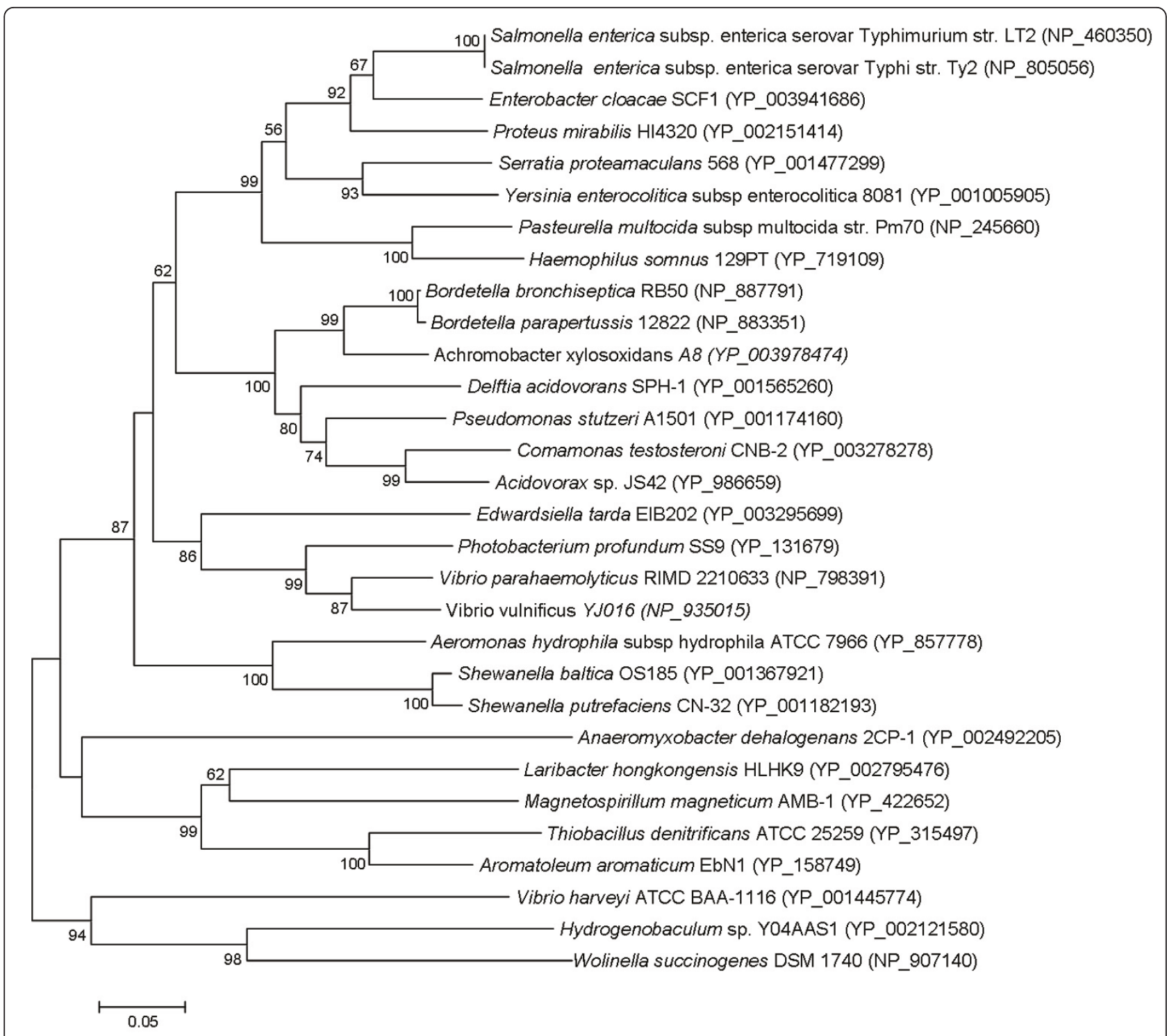

Figure 4 Phylogenetic analysis of $\operatorname{tr} B$ encoded protein in tetrathionate reductase gene cluster in L. hongkongensis HLHK9. Phylogenetic tree showing the relationship of $t$ trB encoded proteins of L. hongkongensis HLHK9 to other species with complete $t$ tr gene cluster constructed by neighbor-joining method. Bootstrap values were calculated from 1000 trees. The scale bar indicates the estimated number of substitutions per 20 amino acids. All names and accession numbers are given as cited in the GenBank database.

with the characteristic two-cysteine motifs are prevalently found in this group of bacteria [55]. The characteristic two-cysteine motifs, CCXXRKXXPL and SXGCXXCT, are found in the C termini of all APS reductases, but not in PAPS reductases [56]. The twocysteine residues are reported to be involved for the binding to the iron-sulfur cluster in plant, $P$. aeruginosa and $M$. tuberculosis, which contribute to the difference in substrate specificity $[58,59]$. However, as this pathway has not been well characterized among $\beta$-Proteobacteria, the role of APS reductase in sulfate assimilation is uncertain in these bacterial taxa. As PAPS reductase has absolute substrate requirement, the product of the APS kinase, PAPS, is essential for $E$. coli to assimilate sulfate [54]. While the genomes of C. violaceum and E. coli are predicted to contain homologues of sulfate adenylyltransferase, APS kinase, PAPS reductase and sulfite reductase, which can encode for a complete sulfate assimilation pathway via PAPS, L. hongkongensis and $N$. meningitidis seem to utilize the other pathway. Sequence analysis revealed that $L$. hongkongensis and $N$. meningitidis contain homologues of APS reductase with the characteristic two-cysteine motifs, and the absence of APS kinase homologue in the genomes suggested that the 


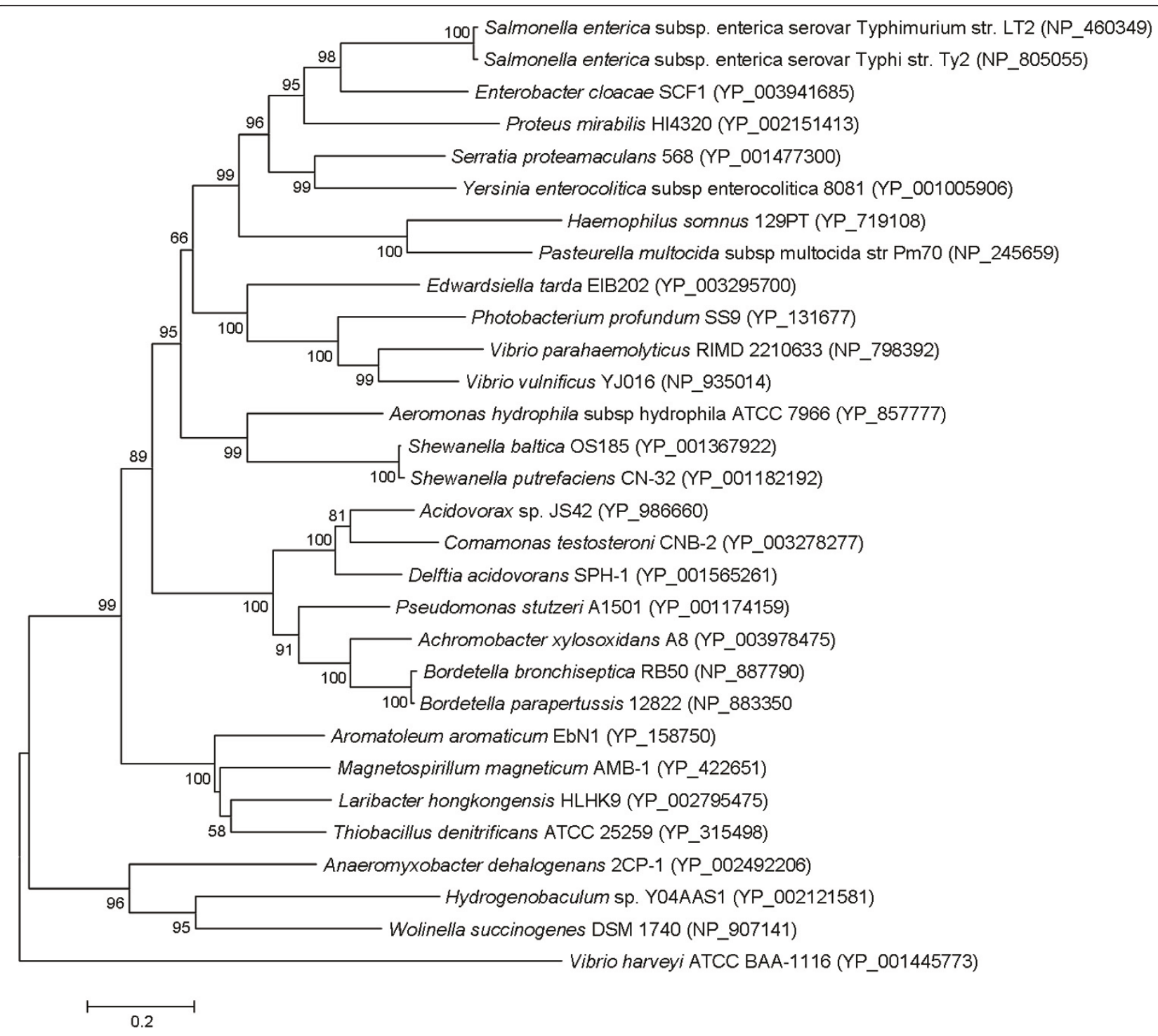

Figure 5 Phylogenetic analysis of $\operatorname{trC}$ encoded protein in tetrathionate reductase gene cluster in L. hongkongensis HLHK9. Phylogenetic tree showing the relationship of ttrC encoded proteins of L. hongkongensis HLHK9 to other species with complete ttr gene cluster constructed by neighbor-joining method. Bootstrap values were calculated from 1000 trees. The scale bar indicates the estimated number of substitutions per 5 amino acids. All names and accession numbers are given as cited in the GenBank database.

reduction of sulfate to sulfite in these bacteria may not involve PAPS intermediates (Figure 6B and Table 6). Although the predicted PAPS reductase in C. violaceum also has the characteristic two-cysteine motifs of APS reductase (Figure 6B), it remains uncertain whether this protein catalyzes PAPS or APS.

\section{Nitrogen metabolism}

Nitrogen is an essential component in organisms that constitutes vital biomolecules such as protein and nucleic acids. Bacteria can utilize different kinds of nitrogen compounds, including inorganic compounds such as ammonia, urea and nitrate; and organic complex compounds such as amino acids and nucleosides, as sources of cellular nitrogen. There are two general pathways found widely in bacteria for ammonia assimilation. After transport across the cytoplasmic membrane into the bacterial cell, ammonia can be incorporated into glutamate or glutamine by glutamate dehydrogenase (GDH) or glutamine synthetase/glutamate synthase (GS/ GOGAT) pathway [32]. The two pathways differ according to the level of nitrogen present in the environment. When nitrogen concentration is high, ammonia assimilation via GDH is preferred as no ATP is consumed when glutamate is produced from oxoglutarate and ammonium. However, when nitrogen concentration is 
A

\section{Sulfate \\ (external)}

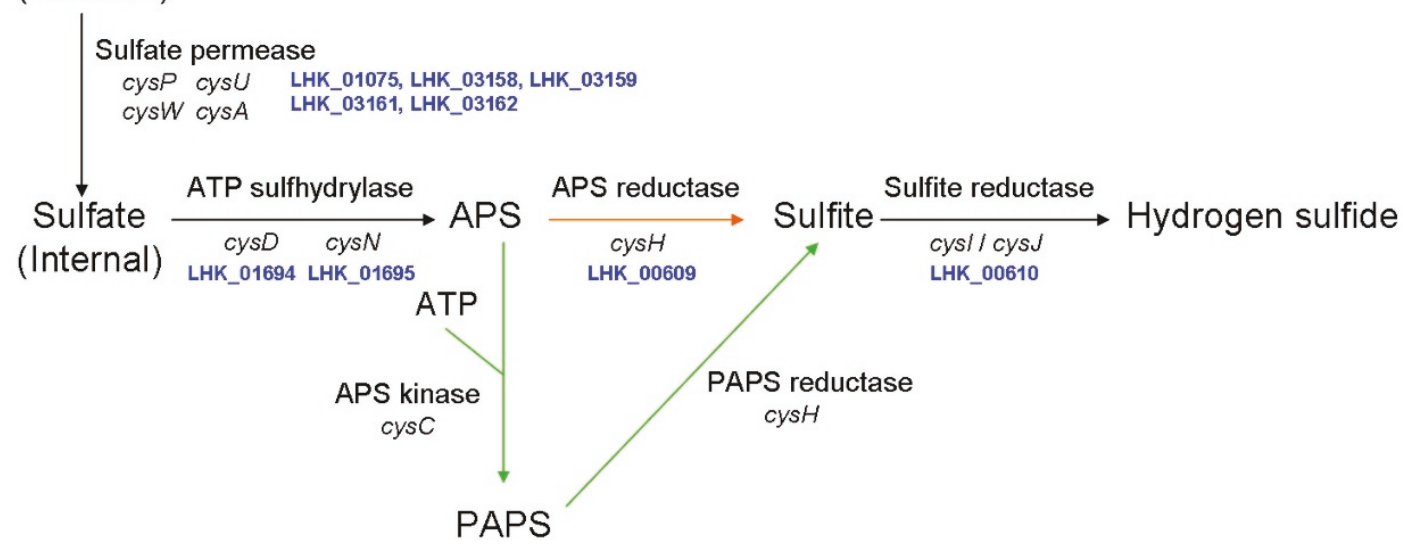

B

Lh AQFGINGFYD SVAARQACCA ARKLEPLGRA LAGR--GAWV TGLRRTQSV- TRSALAVRED 149

Ec EARYGKLWEQ GVEGIEKYND INKVEPMNRA LKELNAQTWF AGLRREQSG- SRANLPVLAI 172

Se EARYGKLWEQ GVEGIEKYNE INKVEPMNRA LKELNAQTWF AGLRREQSG- SRAHLPVLAI 172

Vc EARYGKLWEQ GVEGIERYNQ INKVEPMRRA LDELNISTWF SGLRREQSQ- SRASLPILSV 175

Sp EARFGQLWEQ GLDGLEQYNR LNKVEPMQRA LAELEVGTWF AGLRRSQAS- TREALPILAI 189

Sm AQYGMNGFYE SVEARHACCG VRKLKPLARA LDGA--SYWI TGLRRGQSG- NRATTPFAEA 174

At RNKGLFSFYE - -DGHQECCR IRKVRPLRRA LKGL- -RAWI TGQRKDQSPG TRSEIPVVQV 234

BC AEHGLNAFYE SVELRKSCCH IRKVEPLNRA LADV--GAWV TGQRREQSV- TRAELHEEEQ 158

Nm ESKGRFAFYD SVEARRECCR IRKIEPLNRA IAGA--DAWL TGQRREQSA- TRTELPFAEY 182

CV NFHGINGFYR SVELRKSCCA VRKLEPLKRA LAGR--SAWI TGLRRQQSP- TRQDLADREY 149

* * * * * *

Lh DPVNG -..- - --LVKFSPL ADWSEAEVWE YVHRFSVPYN ALHDRHYPSI GCAPCTRAVA 201

Ec QRGVF - ... - ..--KVLPI IDWDNRTIYQ YLQKHGLKYH PLWDEGYLSV GDTHTTRKWE 222

Se QRGVF-.....-. - KVLPI IDWDNRTVYQ YLQKHGLKYH PLWDQGYLSV GDTHTTRKWE 222

Vc QNGVF-......-KFLPV IDWTNKEVHY YLKDNDLPYH PLWEQGYLSV GDTHTTQKWQ 225

Sp HGTRF -.......-KLLPI IEWSNKDVHL YLTQFNLPYH PLWDQGYVSV GDTHSSKPLE 239

Sm DVERG -...- -.-LIKINPL ADWGIETIQA HVAAEGIPUN PLHSRGYPSI GCEPCTRAIK 226

At DPVFEGLDGG VGSLVKWNPV ANVEGNDVWN FLRTMDVPVN TLHAAGYVSI GCEPCTRAVL 294

Bc DEARG -... - .- IAKYNPL ADWTEADVWA YLKAFDVPVN PLHARGYPSI GCEPCTRAIR 210

Nm DAGRG -... - .- IGKYNPI FDWSEHDVWA YILANNVPYN DLYRQGFPSI GCDPCTRPVK 234

CV DADNG -...- - - LVKFSPL LEWTEAEVWQ YLKENQVPYN ALHDRHYPSI GCAPCTRAIS 201

Figure 6 Sulfate assimilation in L. hongkongensis HLHK9. (A) Sulfate assimilation pathways in bacteria. Two pathways exist in bacteria which differ in the form of sulfate being activated. In one pathway that was once assumed to be the only one, APS is converted to PAPS by APS kinase and subsequently reduced to sulfite by PAPS reductase (green arrow). In the other pathway, APS is directly reduced to sulfite by APS reductase (orange arrow). Homologues of genes found in L. hongkongensis HLHK9 were specified with gene numbers in blue. APS, adenosine 5'adenylylsulfate; PAPS, 3'-phosphoadenylylsulfate. (B) Multiple sequence alignment of predicted APS reductase in L. hongkongensis with other characterized or related bacterial APS and PAPS reductases. Characterized APS reductases include those from Burkholderia cepacia, Arabidopsis thaliana, Rhizobium meliloti whereas characterized PAPS reductases include the one from E. coli. Only the selected region which contains twocysteine motifs, CCXXRKXXPL and SXGCXXCT, in the C-terminal of APS reductase is shown. The conserved cysteine residues are shaded in yellow. The sequences were aligned with ClustalW. The abbreviations used and accession numbers (shown in parentheses) are as follows: At, A. thaliana (GenBank:NP_193930); BC, B. cenocepacia J2315 [GenBank:YP_002231786]; CV, C. violaceum ATCC 12472 [GenBank:NP_903244]; Ec, E. coli K-12 MG1655, [GenBank:NP_417242]; Lh, L. hongkongensis HLHK9 [GenBank:YP_002794611]; Nm, N. meningitidis MC58, [GenBank:NP_274183]; Se, Salmonella enterica subsp. enterica serovar Newport str. SL317 [GenBank:ZP_02697826]; Sp, Shewenella putrefaciens 200 [GenBank:ZP_01705880]; Sm, Rhizobium (Sinorhizobium meliloti 1021) [GenBank:NP_385050] and Vc, Vibrio cholera TM 11079-80 [GenBank:ZP_04409338]. 
Table 6 Comparison of sulfur metabolism deduced from the genomes of L. hongkongensis, N. meningitidis, $N$. gonorrhoeae, C. violaceum, E. coli and C. jejuni

\begin{tabular}{|c|c|c|c|c|c|c|c|}
\hline Pathway/enzyme & Gene(s) & $\begin{array}{l}\text { L. hongkongensis } \\
\text { HLHK9 }\end{array}$ & $\begin{array}{l}\text { C. violaceum } \\
\text { ATCC } 12472\end{array}$ & $\begin{array}{l}\text { N. gonorrhoeae } \\
\text { FA } 1090\end{array}$ & $\begin{array}{l}\text { N. meningitidis } \\
\text { MC58 }\end{array}$ & $\begin{array}{l}\text { E. coli K12 } \\
\text { MG1655 }\end{array}$ & $\begin{array}{l}\text { C. jejuni NCTC } \\
11168\end{array}$ \\
\hline \multicolumn{8}{|l|}{ Sulfate assimilation } \\
\hline $\begin{array}{l}\text { sulfate } \\
\text { adenylyltransferase }\end{array}$ & cysD, cys N & + & + & - & + & + & + \\
\hline APS kinase & cysC & - & + & - & - & + & + \\
\hline PAPS reductase & $c y s H^{a}$ & - & $?^{b}$ & - & - & + & - \\
\hline APS reductase & $c y s H^{a}$ & + & $?^{b}$ & - & + & - & - \\
\hline Sulfite reductase & cysl, cys」 & + & + & + & + & + & - \\
\hline \multicolumn{8}{|l|}{ Sulfate transport } \\
\hline $\begin{array}{l}\text { ATP binding } \\
\text { protein CysA }\end{array}$ & cysA & + & + & + & + & + & - \\
\hline $\begin{array}{l}\text { Permease protein } \\
\text { CysU }\end{array}$ & cysU & + & + & + & + & + & - \\
\hline $\begin{array}{l}\text { Permease protein } \\
\text { CysW }\end{array}$ & cysW & + & + & + & + & + & - \\
\hline $\begin{array}{l}\text { Sulfate binding } \\
\text { protein CysP }\end{array}$ & cysP & + & + & + & + & + & - \\
\hline
\end{tabular}

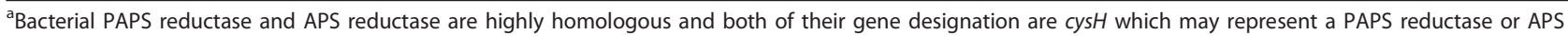
reductase [58].

${ }^{\text {b} P r e d i c t e d ~ a m i n o ~ a c i d ~ s e q u e n c e s ~ e n c o d e d ~ b y ~} \mathrm{cysH}$ (CV_3574) in C. violaceum has the characteristic two-cysteine motifs of APS reductase and the presence of cys $C$ suggests an ambiguity (represent by "?") in the identity of CV_3574 as PAPS or APS reductase.

low, which is the case in most natural environment, ammonia is assimilated through GS/GOGAT pathway. L-glutamine is produced from L-glutamic acid and ammonia by GS in utilizing ATP and two molecules of L-glutamic acid are subsequently synthesized from Lglutamine and oxoglutarate by GOGAT because GDH has a lower affinity for ammonia. Similar to E. coli, $L$. hongkongensis has genes that participated in GDH and GS/GOGAT pathways, including $g d h A$ that encodes NADP-dependent glutamate dehydrogenase, gltB/gltD that encode glutamate synthase and $g \ln A$ that encodes glutamine synthetase (Table 7). On the other hand, the genomes of $C$. violaceum and $C$. jejuni contain only genes in GS/GOGAT pathway whereas those of $N$. meningitidis and $N$. gonorrhoeae contain solely genes of GS pathway. The ability of L. hongkongensis to utilize nitrogen is quite diverse. The existence of both pathways in L. hongkongnesis suggests an importance of ammonia metabolism in the living environments that it may encounter. Ammonia can be found in natural environment such as natural water and being the form of excretory waste in fish, where L. hongkongensis had been reported to be isolated from $[6,10,60]$.

In addition to its presence in the natural environment, ammonia can also be provided by alternative nitrogen sources such as urea. Urea can be hydrolyzed to ammonia and carbon dioxide by urease, in which a complete urease gene cluster is found in L. hongkongensis and none in N. meningitidis, $N$. gonorrhoeae, C. violaceum, E. coli and C. jejuni (Table 7). Ammonia formed in this process not only can provide nutrient nitrogen, but may also help L. hongkongensis to resist acid shock during its transit through the highly acidic environment of stomach by raising $\mathrm{pH}$. With alternative way to metabolize different nitrogen source such as from urea, L. hongkongensis can gain some survival advantages under nitrogen-limited conditions. The dual role in acid resistance and nitrogen metabolism of urease was evident in bacteria such as Streptococcus salivarius, Helicboacter pylori and Yersinia enterocolitica [61-63]. Investigation into the roles of urease in L. hongkongensis can provide insights towards the interplay of both functions and understanding about its survival strategy. Urea can be found in various environments in which L. hongkongensis can be found, including natural water and human host, where urea is present in a range of concentration in different parts ranging from saliva, stomach, blood to urine [64-67].

Alternatively, nitrate is another common form of nitrogen compounds found in the environment. By reducing nitrate, the majority of bacteria can incorporate nitrogen into building blocks, produce energy for cellular processes or dissipate excess energy by respiration [68]. There are three types of bacterial nitrate reductases which are classified according to their localizations and functions, namely the assimilatory (Nas type), membrane-bound (Nar-type) and periplasmic (Nap-type), of which the Nas type is used for incorporating nitrate into building blocks $[68,69]$. In the assimilatory pathway, nitrate is first converted to nitrite by assimilatory nitrate 
Table 7 Comparison of nitrogen metabolism deduced from the genomes of L. hongkongensis, N. meningitidis, $N$. gonorrhoeae, C. violaceum, E. coli and C. jejuni

\begin{tabular}{|c|c|c|c|c|c|c|c|}
\hline Enzyme & Gene(s) & $\begin{array}{l}\text { L. hongkongensis } \\
\text { HLHK9 }\end{array}$ & $\begin{array}{l}\text { C. violaceum } \\
\text { ATCC } 12472\end{array}$ & $\begin{array}{l}\text { N. gonorrhoeae } \\
\text { FA } 1090\end{array}$ & $\begin{array}{l}\text { N. meningitidis } \\
\text { MC58 }\end{array}$ & $\begin{array}{l}\text { E. coli K12 } \\
\text { MG } 1655\end{array}$ & $\begin{array}{l}\text { C. jejuni NCTC } \\
11168\end{array}$ \\
\hline $\begin{array}{l}\text { Glutamate } \\
\text { dehydrogenase }\end{array}$ & gdhA & + & - & + & + & + & - \\
\hline Glutamate synthase & gltB/gltD & + & + & - & - & + & + \\
\hline Glutamine synthetase & $g \ln A$ & + & + & + & + & + & + \\
\hline \multicolumn{8}{|l|}{ Nitrate reductase } \\
\hline $\begin{array}{l}\text { Membrane-bound } \\
\text { Nar type }\end{array}$ & narGHJI ${ }^{a}$ & - & + & - & - & + & - \\
\hline $\begin{array}{l}\text { Periplamsic Nap } \\
\text { type }\end{array}$ & nap $A B C D^{\mathrm{b}}$ & + & napA only & - & - & + & + \\
\hline Nitrite reductase & $\begin{array}{l}\text { nrfA/nifB/ } \\
\text { aniA/nirk }\end{array}$ & - & + & + & + & + & - \\
\hline Nitric oxide reductase & norB & - & + & + & + & - & - \\
\hline Urease & ureABC ${ }^{\mathrm{C}}$ & + & - & - & - & - & - \\
\hline
\end{tabular}

${ }^{\mathrm{a}}$ The basic gene components for membrane-bound type nitrate reductase to be regarded as functional [68]

${ }^{\mathrm{b}}$ The basic gene components for periplasmic type nitrate reductase to be regarded as functional [68]

'The basic gene components for urease to be regarded as functional [77]

reductase and then to ammonium by nitrite reductase such that it can be incorporated into cell materials. Absence of the genes that encode Nas type nitrate reductase and nitrite reductase in L. hongkongensis genome suggested that no assimilatory pathway is present. For the respiratory pathway which mainly involved Nar and Nap type, while E. coli contains both types of nitrate reductases, L. hongkongensis and $C$. jejuni contain only periplasmic nitrate reductase whereas $C$. violaceum contains the membrane-bound type (Table 7). Even though C. violaceum contains napA that belongs to Nap system, the absence of other gene components suggested that this pathway is incomplete and probably non-functional. On the other hand, no homologues of nitrate reductases are found in $N$. meningitidis and $N$. gonorrhoeae. The membrane-bound nitrate reductase, encoded by NarGHI operon, can be found in many nitrate-respiring and denitrifying bacteria and functions as the generator of proton motive force by coupling nitrate reduction in respiration. In contrast to Nar, the function of Nap is much diverse and appears to differ among bacteria. Apart from its involvement in anaerobic respiration in bacteria such as E. coli, it can have other physiological roles such as participating in redox balancing for optimal bacterial growth under certain physiological conditions and aerobic denitrification switch from aerobic respiration to denitrification or scavenges nitrate in some pathogenic bacteria [68]. The gene composition and ordering of nap gene cluster shows heterogenicity amongst different bacteria, with napD and $n a p A$ as the only genes that are always found in the cluster [68]. In L. hongkongensis, it is predicted that nap operon contains 7 genes, napFDAGHBC, with the same gene composition and order as in E. coli. The ability for nitrate reduction in L. hongkongensis suggested that Nap type nitrate reductase is functional $[1,3,11]$. Apart from the above pathways, an absence of nitric oxide reductase in L. hongkongensis suggested that dissimilatory pathway for the production of dinitrogen is not operational.

\section{Conclusions}

The L. hongkongensis genome possesses a variety of genes and pathways for carbohydrate, amino acid and lipid metabolism, respiratory chain and sulfur and nitrogen metabolism. These allow the bacterium to utilize various substrates for energy production and survive in different environmental niches.

\section{Methods}

CDSs identified in the L. hongkongensis genome were annotated as described in our previous publication and classified functionally according to the COG methodology [11]. Annotated genes were mapped to pathways according to the Kyoto Encyclopedia of Genes and Genomes (KEGG) database and MetaCyc to help identify metabolic pathways, and refined with thorough literature mining and experimental data [70,71]. When "gap" exists in the metabolic pathways, reciprocal-best-hit search was adopted to identify orthologues using experimentally verified protein sequence as query. CDSs belonging to metabolism-related COG clusters (C, G, E, $\mathrm{I}$, and $\mathrm{P}$ ) were selected for further examination and review. Other CDSs of potential interest were identified by keyword search using the names of common amino acids, carbohydrates, nucleotides, coenzymes, lipids, inorganic ions and metabolites. Manual annotation and analysis of the assigned function was performed by sequence similarity search using BLAST against the 
NCBI nr database, and assisted by conserved domain search (CD-search), identification of signature sequence motifs and sequence analysis using InterProScan. Localization patterns were predicted using PSORTb where appropriate [72]. Comparison of CDSs belonging to metabolism-related COG clusters among L. hongkongensis HLHK9, C. violaceum ATCC 12472, N. meningitidis MC58, N. gonorrhoeae FA 1090, E. coli K12 MG1655 and C. jejuni NCTC 11168 was performed using KEGG database, MetaCyc and Integrated Microbial Genomes (IMG) database [73]. Phylogenetic trees were constructed by the neighbor-joining method with MEGA 4.0 using Kimura's two-parameter correction for $16 \mathrm{~S}$ rRNA gene and Poisson correction for tetrathionate reductase [74]. 1553 nucleotide positions of 16S rRNA gene, and 1026, 233 and 389 amino acid positions of $\operatorname{ttr} A, \operatorname{ttr} B$ and $\operatorname{tr} C$ genes encoded proteins respectively were included in the analysis.

\section{List of abbreviations}

Acetyl-CoA: acetyl-coenzyme A; ACP: acyl-carrier protein; Acyl-CoA: acylcoenzyme A; ATP: adenosine triphosphate; APS: adenosine 5'-adenylylsulfate; CDS(s): coding sequence(s); CFA: cyclopropane fatty-acyl-phospholipid; COG: cluster of Orthologous Group; DMS: dimethyl sulfide; DMSO:

dimethylsulfoxide; DNA: deoxyribonucleic acid; ED: Entner-Doudoroff; El: enzyme I; EMP: Embden-Meyerhof-Parnas; FAD: flavin adenine dinucleotide; FabA: 3-hydroxydecanoyl-(acyl-carrier-protein)-dehydratase; FabB: hydroxylacyl-(acyl-carrier-protein) synthase I; FabM: trans-2: cis-3-decenoylACP isomerase; Fabz: beta-hydroxyacyl-(acyl-carrier-protein) dehydratase; FabF: beta-ketoacyl-(acyl carrier protein) synthase II; GDH: glutamate dehydrogenase; GS/GOGAT: glutamine synthetase/glutamate synthase; HPr: phosphocarrier protein; HPrK: phosphocarrier protein kinase/phosphorlyase; KEGG: Kyoto Encyclopedia of Genes and Genomes; NADH: nicotiamide adenine dinucleotide; NAGK: N-acetyl-L-glutamate kinase; NAGK-20: N-acetylL-glutamate kinase with higher expression at $20^{\circ} \mathrm{C}$; NAGK-37: N-acetyl-Lglutamate kinase with higher expression at $37^{\circ} \mathrm{C}$; Nas: assimilatory nitrate reductase; Nar: membrane-bound nitrate reductase; Nap: periplasmic nitrate reductase; NDH: NADH dehydrogenase; NPr: variant of phosphocarrier protein; PAPS: 3'-phosphoadenylylsulfate; PPP: pentose phosphate pathway; PTS: phosphotransferase system; TCA: tricarboxylic acid; Sec: selenocysteine; UFA(s): unsaturated fatty acid(s)

\section{Acknowledgements}

This work is partly supported by the Research Grant Council Grant, Committee for Research and Conference Grant and University Development Fund, The University of Hong Kong; the HKSAR Research Fund for the Control of Infectious Diseases of the Health, Welfare and Food Bureau. We are grateful to support from the Genome Research Centre, The University of Hong Kong, and the generous support of Mrs. Carol Yu, Professor Richard Yu, Mr. Hui Hoy and Mr. Hui Ming in the genomic sequencing platform.

\section{Author details}

'Department of Microbiology, The University of Hong Kong, Hong Kong.

${ }^{2}$ State Key Laboratory of Emerging Infectious Diseases, Hong Kong. ${ }^{3}$ Research Centre of Infection and Immunology, The University of Hong Kong, Hong Kong. ${ }^{4}$ Carol Yu Centre of Infection, The University of Hong Kong, Hong Kong.

\section{Authors' contributions}

PCW, KYY and SKL designed and supervised the study. SOC and JLT annotated the genome. HT performed bioinformatics analysis. SOC and PCW drafted the manuscript. All authors read, corrected and approved the final manuscript.

\section{Competing interests}

The authors declare that they have no competing interests.

Received: 30 December 2010 Accepted: 19 April 2011

Published: 19 April 2011

\section{References}

1. Yuen KY, Woo PC, Teng JL, Leung KW, Wong MK, Lau SK: Laribacter hongkongensis gen. nov., sp nov., a novel Gram-negative bacterium isolated from a cirrhotic patient with bacteremia and empyema. J Clin Microbiol 2001, 39:4227-4232.

2. Lau SK, Woo PC, Hui WT, Li MW, Teng JL, Que TL, Luk WK, Lai RW, Yung RW, Yuen KY: Use of cefoperazone MacConkey agar for selective isolation of Laribacter hongkongensis. J Clin Microbiol 2003, 41:4839-4841.

3. Woo PC, Kuhnert P, Burnens AP, Teng JL, Lau SK, Que TL, Yau HH, Yuen KY: Laribacter hongkongensis: a potential cause of infectious diarrhea. Diagn Microbiol Infect Dis 2003, 47:551-556.

4. Woo PC, Lau SK, Teng JL, Que TL, Yung RW, Luk WK, Lai RW, Hui WT, Wong SS, Yau HH, Yuen KY: Association of Laribacter hongkongensis in community-acquired gastroenteritis with travel and eating fish: a multicentre casecontrol study. Lancet 2004, 363:1941-1947.

5. Woo PC, Lau SK, Teng JL, Yuen KY: Current status and future directions for Laribacter hongkongensis, a novel bacterium associated with gastroenteritis and traveller's diarrhoea. Curr Opin Infect Dis 2005, 18:413-419.

6. Lau SK, Woo PC, Fan RY, Lee RC, Teng JL, Yuen KY: Seasonal and tissue distribution of Laribacter hongkongensis, a novel bacterium associated with gastroenteritis, in retail freshwater fish in Hong Kong. Int J Food Microbiol 2007, 113:62-66.

7. Teng $J$, Woo PC, Ma SS, Sit TH, Ng LT, Hui WT, Lau SK, Yuen KY: Ecoepidemiology of Laribacter hongkongensis, a novel bacterium associated with gastroenteritis. J Clin Microbiol 2005, 43:919-922.

8. Lau SK, Lee LC, Fan RY, Teng JL, Tse CW, Woo PC, Yuen K-Y: Isolation of Laribacter hongkongensis, a novel bacterium associated with gastroenteritis, from Chinese tiger frog. Int J Food Microbiol 2009, 129:78-82

9. Feng JL, Yan H, Chowdhury N, Neogi SB, Yamasaki S, Shi L, Hu J, Chen Q: Identification and characterization of integron-associated antibiotic resistant Laribacter hongkongensis isolated from aquatic products in China. Int J Food Microbiol 2010, 144(3):337-341.

10. Lau SK, Woo PC, Fan RY, Ma SS, Hui WT, Au SY, Chan LL, Chan JY, Lau AT, Leung KY, Pun TC, She HH, Wong CY, Wong LL, Yuen KY: Isolation of Laribacter hongkongensis, a novel bacterium associated with gastroenteritis, from drinking water reservoirs in Hong Kong. Journal of Applied Microbiology 2007, 103:507-515.

11. Woo PC, Lau SK, Tse H, Teng JL, Curreem SO, Tsang AK, Fan RY, Wong GK, Huang Y, Loman NJ, Snyder LA, Cai JJ, Huang JD, Mak W, Pallen MJ, Lok S, Yuen KY: The complete genome and proteome of Laribacter hongkongensis reveal potential mechanisms for adaptations to different temperatures and habitats. PLOS Genet 2009, 5:e1000416.

12. Tettelin H, Saunders NJ, Heidelberg J, Jeffries AC, Nelson KE, Eisen JA, Ketchum KA, Hood DW, Peden JF, Dodson RJ, Nelson WC, Gwinn ML, DeBoy R, Peterson JD, Hickey EK, Haft DH, Salzberg SL, White O, Fleischmann RD, Dougherty BA, Mason T, Ciecko A, Parksey DS, Blair E,

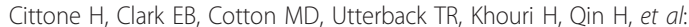
Complete genome sequence of Neisseria meningitidis serogroup B strain MC58. Science 2000, 287:1809-1815.

13. Brazilian National Genome Project Consortium: The complete genome sequence of Chromobacterium violaceum reveals remarkable and exploitable bacterial ada.ptability. Proc Natl Acad Sci 2003, 100:11660-11665.

14. Hayashi T, Makino K, Ohnishi M, Kurokawa K, Ishii K, Yokoyama K, Han CG, Ohtsubo E, Nakayama K, Murata T, Tanaka M, Tobe T, Lida T, Takami H, Honda T, Sasakawa C, Ogasawara N, Yasunaga T, Kuhara S, Shiba T, Hattori $\mathrm{M}$, Shinagawa $\mathrm{H}$ : Complete genome sequence of enterohemorrhagic Escherichia coli 0157:H7 and genomic comparison with a laboratory strain K-12. DNA Res 2001, 8:11-22.

15. Parkhill J, Wren BW, Mungall K, Ketley JM, Churcher C, Basham D, Chillingworth T, Davies RM, Feltwell T, Holroyd S, Jagels K, Karlyshev AV, Moule S, Pallen MJ, Penn CW, Quail MA, Rajandream MA, Rutherford KM, 
van Vliet AH, Whitehead S, Barrel BG: The genome sequence of the foodborne pathogen Campylobacter jejuni reveals hypervariable sequences. Nature 2000, 403:665-668.

16. Janda JM: Aeromonas and Plesiomonas. In Molecular Medical Microbiology. Edited by: Sussman M. San Diego: Academic Press; 2001:1237-1270.

17. von Graevenizta A, Zbinden R, Mutters R: Actinobacillus, Capnocytophaga, Eikenella, Kingella, Pasteurella, and Other fastidious or rarely encountered Gram-negative rods. In Manual of clinical microbiology.. 9 edition. Edited by: Murray PR. Washington D.C.: ASM Press; 2007:621-635.

18. Fitzgerald C, Nachamkin I: Campylobacter and Arcobacter. In Manual of clinical microbiology.. 9 edition. Edited by: Murray PR. Washington D.C.: ASM Press; 2007:933-946

19. Romano AH, Conway T: Evolution of carbohydrate metabolic pathways. Res Microbiol 1996, 147:448-455

20. Parkhill J, Sebaihia M, Preston A, Murphy LD, Thomson N, Harris DE, Holden MT, Churcher CM, Bentley SD, Mungall KL, Cerdeno-Tarraga AM, Temple L, James K, Harris B, Quail MA, Achtman M, Atkin R, Baker S, Basham D, Bason N, Cherevach I, Chillingworth T, Collins M, Cronin A, Davis P, Doggett J, Feltwell T, Goble A, Hamlin N, Hauser H, et al: Comparative analysis of the genome sequences of Bordetella pertussis, Bordetella parapertussis and Bordetella bronchiseptica. Nat Genet 2003, 35:32-40.

21. Baart GJ, Zomer B, de Haan A, van der Pol LA, Beuvery EC, Tramper J, Martens DE: Modeling Neisseria meningitidis metabolism: from genome to metabolic fluxes. Genome Biol 2007, 8:R136.

22. Barabote RD, Saier MH Jr: Comparative genomic analyses of the bacterial phosphotransferase system. Microbiol Mol Biol Rev 2005, 69:608-634.

23. Janausch IG, Zientz E, Tran QH, Kroger A, Unden G: $\mathrm{C}_{4}$-dicarboxylate carriers and sensors in bacteria. Biochim Biophys Acta 2002, 1553:39-56.

24. Dimroth P, Schink B: Energy conservation in the decarboxylation of dicarboxylic acids by fermenting bacteria. Arch Microbiol 1998, 170:69-77.

25. Bock A, Forchhammer K, Heider J, Leinfelder W, Sawers G, Veprek B, Zinoni F: Selenocysteine: the 21st amino acid. Mol Microbiol 1991, 5:515-520.

26. Kryukov GV, Castellano S, Novoselov SV, Lobanov AV, Zehtab O, Guigo R, Gladyshev VN: Characterization of mammalian selenoproteomes. Science 2003, 300:1439-1443.

27. Hatfield DL, Gladyshev VN: How selenium has altered our understanding of the genetic code. Mol Cell Biol 2002, 22:3565-3576.

28. Zhang Y, Romero H, Salinas G, Gladyshev VN: Dynamic evolution of selenocysteine utilization in bacteria: a balance between selenoprotein loss and evolution of selenocysteine from redox active cysteine residues. Genome Biol 2006, 7:R94.

29. Zhang Y, Gladyshev VN: An algorithm for identification of bacterial selenocysteine insertion sequence elements and selenoprotein genes. Bioinformatics 2005, 21:2580-2589

30. Hazel JR: Thermal adaptation in biological membranes: is homeoviscous adaptation the explanation? Annu Rev Physiol 1995, 57:19-42.

31. Sajbidor J: Effect of some environmental factors on the content and composition of microbial membrane lipids. Crit Rev Biotechnol 1997, 17:87-103.

32. Kim B, Gadd GM: Bacterial Physiology and Metabolism. Cambridge: Cambridge University Press; 2008.

33. Feng Y, Cronan JE: Escherichia coli unsaturated fatty acid synthesis: complex transcription of the $f a b A$ gene and in vivo identification of the essential reaction catalyzed by FabB. J Biol Chem 2009, 284(43):29526-35.

34. Wang H, Cronan JE: Functional replacement of the FabA and FabB proteins of Escherichia coli fatty acid synthesis by Enterococcus faecalis FabZ and FabF homologues. J Biol Chem 2004, 279:34489-34495.

35. Marrakchi $\mathrm{H}$, Choi KH, Rock CO: A new mechanism for anaerobic unsaturated fatty acid formation in Streptococcus pneumoniae. J Biol Chem 2002, 277:44809-44816.

36. Morgan-Kiss RM, Cronan JE: The Lactococcus lactis FabF fatty acid synthetic enzyme can functionally replace both the FabB and FabF proteins of Escherichia coli and the FabH protein of Lactococcus lactis. Arch Microbiol 2008, 190:427-437.

37. Zhu L, Cheng J, Luo B, Feng S, Lin J, Wang S, Cronan JE, Wang H: Functions of the Clostridium acetobutylicium FabF and FabZ proteins in unsaturated fatty acid biosynthesis. BMC Microbiology 2009, 9:119.

38. Rahman MM, Kolli VS, Kahler CM, Shih G, Stephens DS, Carlson RW: The membrane phospholipids of Neisseria meningitidis and Neisseria gonorrhoeae as characterized by fast atom bombardment mass spectrometry. Microbiology 2000, 146(Pt 8):1901-1911.

39. Barkan D, Liu Z, Sacchettini JC, Glickman MS: Mycolic acid cyclopropanation is essential for viability, drug resistance, and cell wall integrity of Mycobacterium tuberculosis. Chem Biol 2009, 16:499-509.

40. Chang YY, Cronan JE Jr: Membrane cyclopropane fatty acid content is a major factor in acid resistance of Escherichia coli. Mol Microbiol 1999, 33:249-259.

41. Schmehl M, Jahn A, Meyer zu Vilsendorf A, Hennecke S, Masepohl B, Schuppler M, Marxer M, Oelze J, Klipp W: Identification of a new class of nitrogen fixation genes in Rhodobacter capsulatus: a putative membrane complex involved in electron transport to nitrogenase. Mol Gen Genet 1993, 241:602-615.

42. Bruggemann H, Baumer S, Fricke WF, Wiezer A, Liesegang H, Decker I, Herzberg C, Martinez-Arias R, Merkl R, Henne A, Gottschalk G: The genome sequence of Clostridium tetani, the causative agent of tetanus disease. Proc Natl Acad Sci USA 2003, 100:1316-1321.

43. Kumagai $H$, Fujiwara T, Matsubara H, Saeki K: Membrane localization, topology, and mutual stabilization of the $\operatorname{rnfABC}$ gene products in Rhodobacter capsulatus and implications for a new family of energycoupling NADH oxidoreductases. Biochemistry 1997, 36:5509-5521.

44. Mclnerney MJ, Rohlin L, Mouttaki H, Kim U, Krupp RS, Rios-Hernandez L, Sieber J, Struchtemeyer CG, Bhattacharyya A, Campbell JW, Gunsalus RP: The genome of Syntrophus aciditrophicus: life at the thermodynamic limit of microbial growth. Proc Natl Acad Sci USA 2007, 104:7600-7605.

45. Myllykallio $\mathrm{H}$, Liebl U: Dual role for cytochrome cbb3 oxidase in clinically relevant proteobacteria? Trends Microbiol 2000, 8:542-543.

46. Lee PA, de Mora SJ: Intracellular dimethylsulfoxide (DMSO) in unicellular marine algae: speculations on its origin and possible biological role. Journal of Phycology 1999, 35:8-18.

47. Shooter PBaD: Photo-oxidation of dimethylsulphide in aqueous solution. Marine Chemistry 1986, 19:343-353.

48. Beller HR, Chain PS, Letain TE, Chakicherla A, Larimer FW, Richardson PM, Coleman MA, Wood AP, Kelly DP: The genome sequence of the obligately chemolithoautotrophic, facultatively anaerobic bacterium Thiobacillus denitrificans. J Bacteriol 2006, 188:1473-1488.

49. Rabus R, Kube M, Heider J, Beck A, Heitmann K, Widdel F, Reinhardt R: The genome sequence of an anaerobic aromatic-degrading denitrifying bacterium, strain EbN1. Arch Microbiol 2005, 183:27-36.

50. Barrett EL, Clark MA: Tetrathionate reduction and production of hydrogen sulfide from thiosulfate. Microbiol Rev 1987, 51:192-205.

51. Winter SE, Thiennimitr P, Winter MG, Butler BP, Huseby DL, Crawford RW, Russell JM, Bevins CL, Adams LG, Tsolis RM, Roth JR, Baumler AJ: Gut inflammation provides a respiratory electron acceptor for Salmonella. Nature 2010, 467:426-429.

52. Furne J, Springfield J, Koenig T, DeMaster E, Levitt MD: Oxidation of hydrogen sulfide and methanethiol to thiosulfate by rat tissues: a specialized function of the colonic mucosa. Biochem Pharmacol 2001, 62:255-259.

53. Levitt MD, Furne J, Springfield J, Suarez F, DeMaster E: Detoxification of hydrogen sulfide and methanethiol in the cecal mucosa. J Clin Invest 1999, 104:1107-1114.

54. Kredich NM, (Ed): Biosynthesis of cysteine. Washington, D.C: American Society for Microbiology; 21996

55. Kopriva S, Buchert T, Fritz G, Suter M, Benda R, Schunemann V, Koprivova A Schurmann P, Trautwein AX, Kroneck PM, Brunold C: The presence of an iron-sulfur cluster in adenosine $5^{\prime}$-phosphosulfate reductase separates organisms utilizing adenosine $5^{\prime}$-phosphosulfate and phosphoadenosine 5'-phosphosulfate for sulfate assimilation. J Biol Chem 2002, 277:21786-21791.

56. Bick JA, Dennis JJ, Zylstra GJ, Nowack J, Leustek T: Identification of a new class of 5'-adenylylsulfate (APS) reductases from sulfate-assimilating bacteria. J Bacteriol 2000, 182:135-142.

57. Williams SJ, Senaratne RH, Mougous JD, Riley LW, Bertozzi CR: 5'adenosinephosphosulfate lies at a metabolic branch point in mycobacteria. J Biol Chem 2002, 277:32606-32615.

58. Kopriva S, Buchert T, Fritz G, Suter M, Weber M, Benda R, Schaller J, Feller U, Schurmann P, Schunemann V, Trautwein AX, Kroneck PM, Brunold C: Plant adenosine $5^{\prime}$-phosphosulfate reductase is a novel iron-sulfur protein. $J$ Biol Chem 2001, 276:42881-42886. 
59. Carroll KS, Gao H, Chen H, Leary JA, Bertozzi CR: Investigation of the ironsulfur cluster in Mycobacterium tuberculosis APS reductase: implications for substrate binding and catalysis. Biochemistry 2005, 44:14647-14657.

60. Shan H, Obbard JP: Ammonia removal from freshwater using nitrifying bacteria enriched from a seawater aquaculture pond. Biotechnol Lett 2003, 25:1469-1471.

61. Williams CL, Preston T, Hossack M, Slater C, McColl KE: Helicobacter pylori utilises urea for amino acid synthesis. FEMS Immunol Med Microbiol 1996 13:87-94.

62. Young GM, Amid D, Miller VL: A bifunctional urease enhances survival of pathogenic Yersinia enterocolitica and Morganella morganii at low pH. $J$ Bacteriol 1996, 178:6487-6495.

63. Chen YY, Weaver CA, Burne RA: Dual functions of Streptococcus salivarius urease. J Bacteriol 2000, 182:4667-4669.

64. Dawes C, Dibdin GH: Salivary concentrations of urea released from a chewing gum containing urea and how these affect the urea content of gel-stabilized plaques and their $\mathrm{pH}$ after exposure to sucrose. Caries Res 2001, 35:344-353.

65. Neithercut WD, el Nujumi AM, McColl KE: Measurement of urea and ammonium concentrations in gastric juice. J Clin Pathol 1993, 46:462-464.

66. Mackay EM, Mackay LL: The concentration of urea in the blood of normal individuals. J Clin Invest 1927, 4:295-306.

67. Mobley HL, Hausinger RP: Microbial ureases: significance, regulation, and molecular characterization. Microbiol Rev 1989, 53:85-108.

68. Richardson DJ, Berks BC, Russell DA, Spiro S, Taylor CJ: Functional, biochemical and genetic diversity of prokaryotic nitrate reductases. Cell Mol Life Sci 2001, 58:165-178.

69. Stolz JF, Basu P: Evolution of nitrate reductase: molecular and structural variations on a common function. Chembiochem 2002, 3:198-206.

70. Kanehisa M, Goto S: KEGG: Kyoto encyclopedia of genes and genomes. Nucleic Acids Res 2000, 28(1):27-30.

71. Caspi R, Altman T, Dale JM, Dreher K, Fulcher CA, Gilham F, Kaipa P, Karthikeyan AS, Kothari A, Krummenacker M, Latendresse M, Mueller LA, Paley S, Popescu L, Pujar A, Shearer AG, Zhang P, Karp PD: The MetaCyc database of metabolic pathways and enzymes and the BioCyc collection of pathway/genome databases. Nucleic Acids Res 2010, 38:D473-479.

72. Yu NY, Wagner JR, Laird MR, Melli G, Rey S, Lo R, Dao P, Sahinalp SC, Ester M, Foster LJ, Brinkman FS: PSORTb 3.0: improved protein subcellular localization prediction with refined localization subcategories and predictive capabilities for all prokaryotes. Bioinformatics 2010, 26:1608-1615.

73. Markowitz VM, Chen IA, Palaniappan K, Chu K, Szeto E, Grechkin Y, Ratner A, Anderson I, Lykidis A, Mavromatis K, Ivanova NN, Kyrpides NC: The integrated microbial genomes system: an expanding comparative analysis resource. Nucleic Acids Res 2010, 38:D382-390.

74. Tamura K, Dudley J, Nei M, Kumar S: MEGA4: Molecular Evolutionary Genetics Analysis (MEGA) software version 4.0. Molecular Biology and Evolution 2011, 24:1596-1599.

75. Friedrich T, Scheide D: The respiratory complex I of bacteria, archaea and eukarya and its module common with membrane-bound multisubunit hydrogenases. FEBS Lett 2000, 479:1-5.

76. Melo AM, Bandeiras TM, Teixeira M: New insights into type II NAD(P)H: quinone oxidoreductases. Microbiol Mol Biol Rev 2004, 68:603-616.

77. Mobley HL, Island MD, Hausinger RP: Molecular biology of microbial ureases. Microbiol Rev 1995, 59:451-480.

doi:10.1186/2045-3701-1-16

Cite this article as: Curreem et al: General metabolism of Laribacter hongkongensis: a genome-wide analysis. Cell \& Bioscience 2011 1:16. 